\title{
MILK OF CALCIUM RENAL CYST: CT FINDINGS
}

\author{
RONALD O. BUDE, M.D. \\ MELVYN T. KOROBKIN, M.D.
}

From the Department of Radiology, University of Michigan

Medical Center, Ann Arbor, Michigan

\begin{abstract}
Milk of calcium in the kidney is usually found in association with hydronephrosis or caliceal diverticula. A case of milk of calcium in a renal cyst is presented. Contiguity with an adjacent rib can make it difficult to detect the dependent layered milk of calcium.
\end{abstract}

The appearance of milk of calcium in the kidneys was first reported in 1948 by Holm. ${ }^{1}$ Subsequent articles have described the plain film, ${ }^{2-14}$ ultrasound, ${ }^{15}$ and even the magnetic resonance (MR) appearance. ${ }^{16}$ To our knowledge, only 1 case of computerized tomography (CT) appearance of milk of calcium in a renal cyst has been described. ${ }^{17}$ We report another case of milk of calcium in a renal cyst, emphasizing the potential difficulty of identifying the layered milk of calcium when it is contiguous with an adjacent posterior rib.

\section{Case Report}

During hospitalization for pelvic inflammatory discase, radiographs of the abdomen in a twenty-five-year-old woman showed multiple opaque densities projecting over the left kidney
(Fig. 1A). Retrograde pyelography showed a left renal mass containing a homogeneous, solitary, poorly circumscribed opacity (Fig. 1B). CT showed a left renal cyst with one definite and other possible septations (Fig. 2A). A calcium-fluid level adjacent to a posterior rib was initially not recognized; subsequent recognition was aided by bone-window display (Fig. 2B). Upright film of the abdomen showed multiple calcium-fluid levels (Fig. 3).

\section{Comment}

Milk of calcium consists of a suspension of innumerable microcalculi, consisting of calcium phosphate, calcium carbonate, calcium hydroxyapatite, calcium oxalate, or mixtures of these compounds. ${ }^{15,18}$ It can be found in the gastrointestinal tract (gallbladder and duplication

Figure 1. (A) Supine $a b$ dominal radiograph shows multiple poorly defined opacities (arrows) projecting over region of left kidney. Staghorn calculi were suspected. (B) Retrograde pyelogram shows mass in upper pole of left kidney. Solitary, homogeneous, poorly circumscribed slightly opaque density (arrouss) projects over mass.

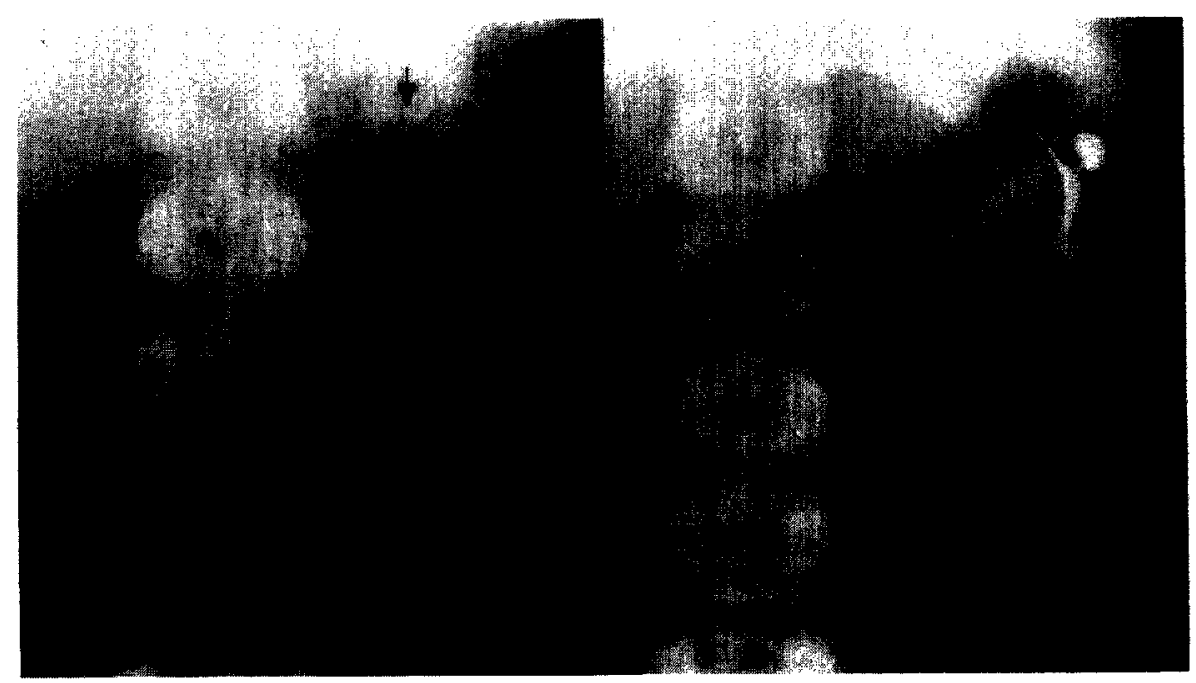


Figure 2. Enhanced $C T$ scan of loculated renal cyst. (A) At soft tissue windows it is difficult to differentiate layered milk of calcium (open arrow) from contiguous rib (closed arrow). (B) At bone window settings milk of calcium is easier to identify.

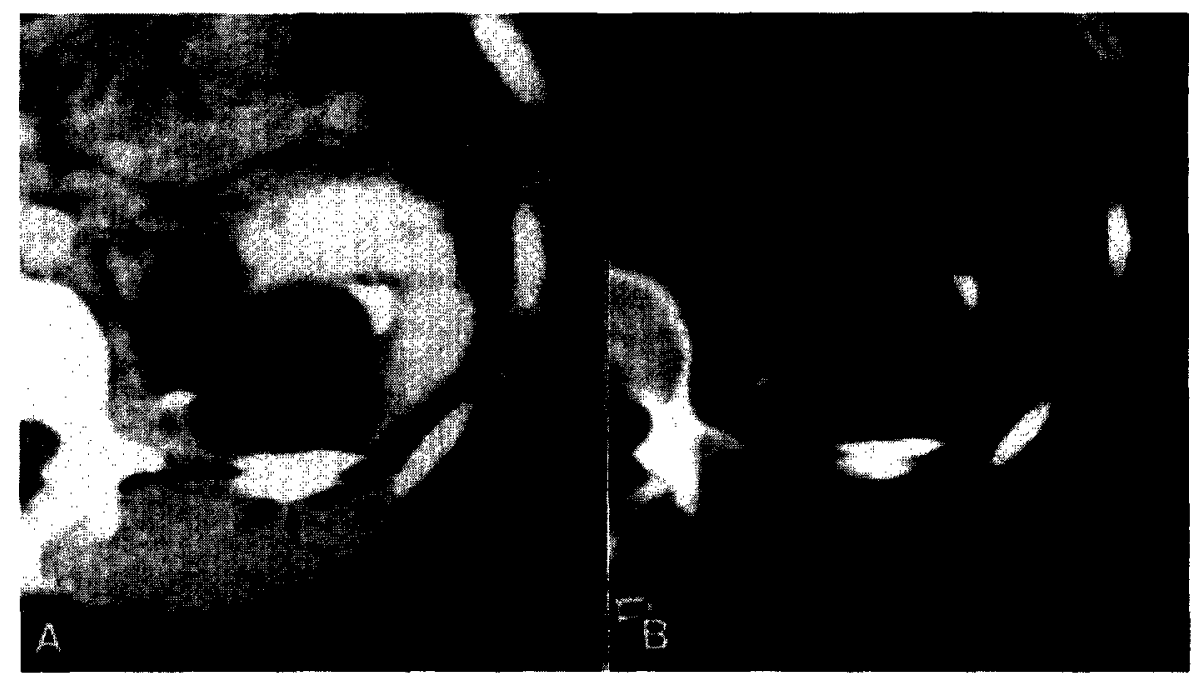

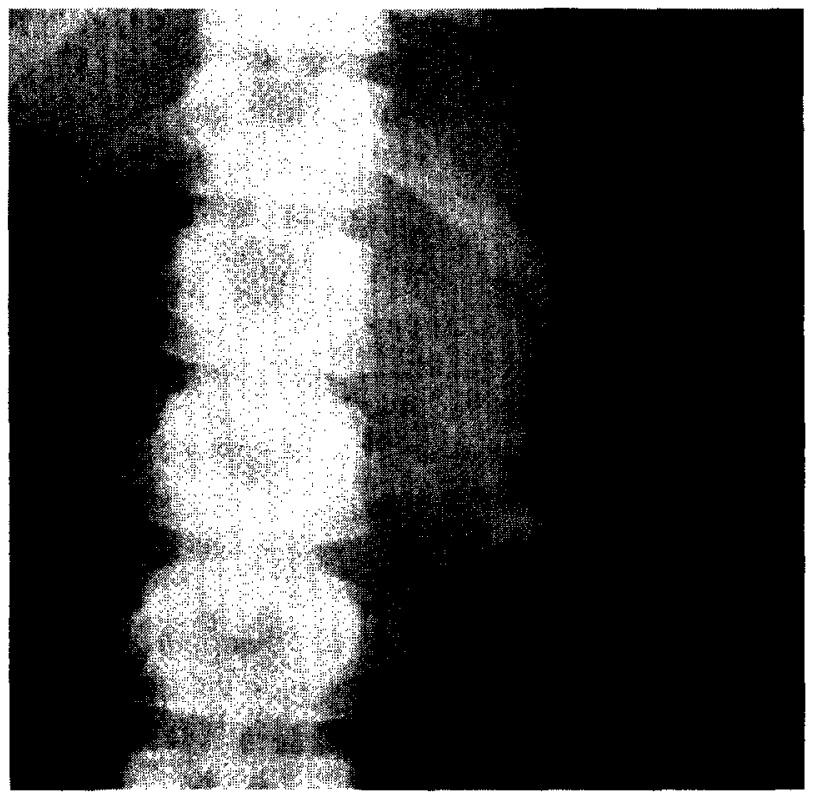

FIGURE 3. Upright abdominal radiograph shows five separate calcium-fluid levels projecting over region of renal mass, confirming gravity-dependent mobility of milk of calcium in multiloculated renal cyst.

cysts), in the urinary tract (pyelogenic cysts, caliceal diverticula, ureteroceles, and in the collecting systems of long-standing hydronephrosis), in bronchogenic cysts, and in adrenal cysts. ${ }^{15}$ Although of unknown pathogenesis, in the gallbladder it is associated with chronic cholecystitis and in the urinary tract, urinary stasis is present. ${ }^{15}$

Numerous case reports and small series describe the plain film appearance of milk of calcium in hydronephrotic kidneys ${ }^{4,7}$ and in renal cysts, ${ }^{2,3,5-14}$ but the cysts are actually caliceal diverticula rather than true renal cysts. Re- cently the CT appearance of milk of calcium in hydronephrosis, ${ }^{18}$ the ultrasound appearance of milk of calcium in both hydronephrosis and renal cysts, ${ }^{15}$ and the MR appearance of milk of calcium renal cyst ${ }^{16}$ have been described. To our knowledge, the CT appearance of milk of calcium in a renal cyst has only been described in one prior report, ${ }^{17}$ where the movable nature of the milk of calcium was demonstrated using supine and prone position scanning.

On radiographic studies of the kidneys, including CT, the diagnosis of milk of calcium is made by noting dependent layering of calcific material ${ }^{9,17}$ which may change in shape with changes of patient position. It is these properties which most reliably serve to distinguish it from other entities exhibiting increased radiographic density (calculi, tumor calcification, and high density renal cysts). ${ }^{9,15,19-21}$

In our case the dependent layering of high density material in the renal cyst due to its contiguity with an adjacent posterior rib was not initially recognized on the CT examination. Bone window views of the same section made it easier to discriminate the rib from the layered milk of calcium. Although prone or decubitus views were not obtained during the CT evaluation, upright plain radiographs of the abdomen confirmed the mobile and gravity-dependent nature of the milk of calcium.

Another feature differentiating our case from the prior report was the multilocular nature of the renal cyst in our patient. The upright plain radiograph demonstrated five contiguous calcium-fluid levels, whereas the supine CT scans showed four such collections as well as at least one well-defined septation dividing the cyst. Since the supine retrograde pyelogram showed 
a single large opaque density, it is likely that several incomplete septations divide the renal cyst in our patient; the possibility of several contiguous noncommunicating cysts, each containing milk of calcium, is a less likely alternative diagnosis.

\section{Ann Arbor, Michigan 48109/0026}

(DR. BUDE)

\section{References}

1. Holm H: On pyelogenic renal cysts, ACTA 29: 87 (1948).

2. Pomerantz RM, Kirschner LP, and Twigg HL: Renal milkof-calcium collection: review of literature and report of case, $\mathrm{J}$ Urol 103: 18 (1970).

3. Murray RL: Milk of calcium in the kidney, AJR 113: 455 (1971).

4. Herman RD, Leoni JV, and Matthews GR: Renal milk of calcium associated with hydronephrosis, AJR 130: 572 (1978).

5. Howell RD: Milk of calcium renal stonc, J Urol 82: 197 (1959).

6. Pullman RAW, and King RJ: Milk of calcium renal stone, AJR 87: 760 (1962).

7. Berg RA: Milk of calcium renal disease, AJR 101: 708 (1967).

8. Garrett RA, and Holland JM: Milk of calcium in caliceal diverticulum, J Urol 109: 927 (1973).
9. Healey T, Way BG, and Grundy WR: Milk of calcium in calycine diverticula, Br J Radiol 53: 845 (1980).

10. Benendo B, and Litwak A: Milk of calcium in a renal cyst, Br J Radiol 37: 70 (1964).

11. Rosenberg MA: Milk of calcium in a renal calyceal diverticulum, AJR 101: 714 (1967).

12. Maurer RM, and Wildin RE: Milk of calcium renal stone, Radiology 84: 274 (1965).

13. Morin LJ, and Albert DJ: Milk of calcium in a renal cyst, J Urol 96: 869 (1966).

14. Henken EM: Milk of calcium in a renal cyst, Radiology 84: 276 (1965).

15. Patriquin $\mathrm{H}$, Lafortune $\mathrm{M}$, and Filiatrault D: Urinary milk of calcium in children and adults: use of gravity-dependent sonography, AJR 144: 407 (1985).

16. Kinard RE, Orrison WW, Brogdon BG, and Kaude JV: MR imaging of milk of calcium renal cyst, JCAT 10: 1057 (1986).

17. Yashiro N, Yoshida $\mathrm{H}$, and Araki T: Bilateral milk of calcium renal cysts: CT findings, JCAT 9: 199 (1985).

18. Sussman SK, Goldberg RP, and Griscom NT: Milk of calcium hydronephrosis in patients with paraplegia and urinary-enteric diversion: CT demonstration, JCAT 10: 257 (1986).

19. Dunnick NR, Korobkin M, Silverman PM, and Foster WL Jr: Computed tomography of high density renal cysts, JCAT 8: 458 (1984).

20. Weyman PJ, McClennan BL, Lee JKT, and Stanley RJ: CT of calcified renal masses, AJR 138: 1095 (1982).

21. Fishman MC, Pollack HM, Arger PH, and Banner MP: High protein content: another cause of CT hyperdense benign renal cyst, JCAT 7: 1103 (1983). 